\title{
Mechanical Properties of Concrete with Recycled Aggregate at Early Ages
}

\author{
Zeger Sierens and Jiabin Li
}

Synopsis: Currently, recycled concrete aggregates (RCAs) are mainly used in some low-grade applications. New high-value-added applications of this kind of material are required. One possible high-end application is in precast prestressed concrete elements. Knowledge on the mechanical properties of concrete with RCAs at early ages is of crucial importance for this purpose. This paper presents a test program to examine the effect of RCAs on the mechanical properties of concrete at early ages. The main variables in the tests are the percentage of RCAs $(0$, $10 \%, 20 \%, 50 \%$ and $100 \%)$ and curing age (1d, 2d, 3d, 7d, 14d and 28d). The compressive strength, splitting tensile strength and modulus of elasticity of the concretes are measured. The test results indicate that the use of RCAs tends to decrease the development of the concrete strength and modulus of elasticity with time, but mainly in the first 7 days. The difference increases with the increase of the percentage of RCAs. The test data are also compared with the models in EN 1992-1-1, ACI 209 and ACI 318. It is found that the models can generally provide satisfactory descriptions of the strength and modulus of elasticity of concrete with RCAs at early ages.

Keywords: recycled concrete aggregates (RCAs), precast concrete, pre-stressed concrete, strength, modulus of elasticity, early ages 
Zeger Sierens is a second-year PhD student in the Department of Civil Engineering, KU Leuven, Belgium. He received his bachelor and master degree from KU Leuven. His PhD research work is focused on the use of recycled concrete aggregates (RCAs) in precast non-prestressed and prestressed concrete elements.

Jiabin $\mathbf{L i}$ is a professor in the Department of Civil Engineering and holder of the Chair in Smart \& Sustainable Infrastructure and Zero-Waste in Construction, KU Leuven, Belgium. He received his PhD degree in Structural Engineering in 2011 from University of Leipzig, Germany. His main research interests include recycling and reuse in construction, smart and sustainable infrastructure, analysis and design of structural concrete, as well as numerical modeling of concrete materials and structures.

\section{INTRODUCTION}

The construction industry uses a lot of natural aggregates to produce concrete. In Flanders (Belgium), due to the lack of natural resources, most of the natural aggregates need to be imported from other countries. This results in a high transportation cost, a high carbon dioxide emission and a high impact on the environment. On the other hand, a large volume of construction and demolition waste (CDW) is produced in Flanders. It is expected that the yearly amount of CDW will increase from 12 to 15 million tons in the next 10 years in Flanders [1]. Previous studies indicated that recycled aggregates derived from crushing CDW have the potential to be a good alternative for natural aggregates in different applications [2,3].

Recycled aggregates can be divided in different categories, that is, mixed aggregates, normal quality recycled concrete aggregates (RCAs) and high-quality RCAs based on the properties of the materials such as the density and the water absorption and/or the abrasion coefficient [1]. Presently, nearly all types of aggregates are mainly used in low-grade applications such as the sub base courses and foundations in the road work. It is reported that about $25 \%$ of the total amount of CDW produced in Flanders can be processed into high quality RCAs. This type of material has the potential to be used in some high-grade applications such as precast concrete structural components [1]. The use of high quality RCAs in precast concrete can further promote the sustainability of precast industry.

Systematic research is necessary to examine the feasibility of the use of high quality RCAs in precast concrete structural components. Precast concrete requires different and generally stricter quality control in comparison with on-site cast concrete. To use RCAs in precast concrete, especially for prestressed structural components, information about the time-dependent material properties of concrete containing RCAs at early ages is required [2]. This paper presents an experimental study on the development of the strength properties and modulus of elasticity of concrete with RCAs at early ages. The effect of RCAs on the properties of concrete is investigated.

\section{EXPERIMENTAL PROGRAM}

A series of tests are designed and performed to investigate the influence of RCAs on the mechanical properties of concrete at early ages.

\footnotetext{
Materials

A rapid hardening cement (CEM I 52.5 R) is used in all concrete mixtures. This type of cement is commonly used in the Flemish precast industry to derive high early concrete strength so that the time required to demold the products can be minimized. The used sand is a mix of river sand and sea sand. The fineness modulus of the sand is 3.07. Two fractions of limestone, i.e., $2-6.3 \mathrm{~mm}$ and $6.3-14 \mathrm{~mm}$, together with the sand are utilized as natural aggregates. The RCAs used in the test are supplied by a recycling plant in Flanders. The size of the RCAs is 6.3$14 \mathrm{~mm}$. In the concrete with RCAs, the coarser fraction of the limestone, i.e., the limestone having the size of 6.3$14 \mathrm{~mm}$ is replaced by RCAs. The used water is normal tap water. A superplasticizer (MasterGlenium 51con 35\%) is also employed to research the required workability of the concrete mixture.

The grading curves of the coarser limestone $(6.3-14 \mathrm{~mm})$ and that of the RCAs are shown in Fig. 1. The sieving test is carried out according to EN 933-1: Tests for geometrical properties of aggregates - Part 1: Determination of particle size distribution - Sieving method. It can be seen that the grading curves of the two materials are very similar. Hence, the influence due to the difference in the grading of the aggregates can be minimized.

In Table 1, some physical properties of the aggregates are presented, which include the apparent density $\left(\rho_{\mathrm{a}}\right)$, overdried density $\left(\rho_{\mathrm{rd}}\right)$, saturated and surface-dried density $\left(\rho_{\mathrm{ssd}}\right)$ as well as the water absorption $\left(\mathrm{WA}_{24}\right)$. The tests are performed according to EN 1097-6: Tests for mechanical and physical properties of aggregates - Determination of particle density and water absorption.
}

\section{Concrete mixtures}

Starting from an existing conventional concrete mixture used in a Flemish precast concrete company, a total of five different concrete mixtures are designed. The difference between various concrete mixtures is the replacing percentage of the RCAs, which varies from $0 \%, 10 \%, 20 \%, 50 \%$ and $100 \%$ (by volume). The mix proportions of the mixtures are shown in Table 2. The concrete mixtures are named RCA followed by a number, which indicates 
the percentage of the RCAs (in percent). For instance, RCA50 means a concrete mixture with $50 \%$ percent of RCAs. The mixture RCA0 implies a concrete without RCAs, which severs as a reference for the concrete production in this study. As mentioned above, the proportioning of the reference mixture is currently utilized in a local precast concrete manufacturer for producing prestressed structural elements.

All the five concrete mixtures have an identical effective water-to-cement ratio (W/ $\left.\mathrm{C}_{\text {eff }}\right)$, which is 0.48 . In the manufacture of the concretes, dry aggregates are used. Therefore, the water absorption of the materials needs to be taken into account to avoid the loss of the workability. This is particular true for the concrete with RCAs since the water absorption of the RCAs is much higher than that of the used limestone. Due to this reason, another part of water called compensation water is added in the concrete mixtures. The amount of the compensation water is determined according to the mass of the aggregates and their water absorption values. It is found in the test that the measured slump values for the concrete mixtures are similar, as shown in Table 2, due to the addition of the compensation water.

\section{Specimens preparation and curing}

All concrete mixtures are prepared and produced in the laboratory using a mixer with maximum capacity of 150 liter. The two-stage mixing approach proposed by Tam et al. [4] is used to prepare the concrete mixtures. For each concrete mixture, a total of 36 cubes (dimension: $150 \times 150 \times 150 \mathrm{~mm})$ and 18 cylinders $(\Phi 150 \times 450 \mathrm{~mm})$ are cast. Amongst of the specimens, 18 cubes are used to determine the concrete compressive strength, the other 18 cubic specimens are used for testing the splitting tensile strength of the concrete, and the 18 cylinders are used to determine the modulus of elasticity of the concrete. For each concrete mixture, all the specimens are cast from the same batch to minimize the variability in the concrete properties.

The specimens are cured in a standard climate room with a temperature of $20{ }^{\circ} \mathrm{C}$ and relative humidity (RH) of 95\% according to EN 12390-2: Testing hardened concrete-Making and curing specimens for strength tests, prior to the test. The mechanical properties of the concretes are tested at a curing age of $1 \mathrm{~d}, 2 \mathrm{~d}, 3 \mathrm{~d}, 7 \mathrm{~d}, 14 \mathrm{~d}$ and $28 \mathrm{~d}$. For each test at a certain curing age, 3 specimens are tested.

\section{Compressive strength}

\section{TEST RESULTS AND DISCUSSION}

The compressive strength tests on the concrete are performed on cubes using a universal compressive machine with a maximal load of $2000 \mathrm{kN}$ according to EN 12390-3: Testing hardened concrete-Compressive strength of test specimens. In addition, tests on cylinders are also conducted after determining the modulus of elasticity of the specimens. The test results on the compressive strength measured from cubes and cylinders are shown in Fig. 2 , respectively, in which each point represents the mean value of the measured data from three test specimens. It can be seen from the figures that the concretes with RCAs show similar development of the compressive strength with time in comparison to the reference concrete without RCAs. The compressive strength of the concretes increases with the increase the curing age; however, the strength increase mainly occurs in the first 7 days, irrespective of the types of the test specimens and the percentage of the RCAs. In other words, the strength increase of the concretes is very limited after 7 days.

Fig. 2 also indicates that for each curing age, the compressive strength of the concretes generally decreases with the increase of the percentage of the RCAs. This is more pronounced for the test data measured on the cylinders. However, the drop in the compressive strength decreases with the increase of the curing age. In the case of RCA10 with cylindrical specimens, the reduction in the measured compressive strength at $1 \mathrm{~d}, 2 \mathrm{~d}, 3 \mathrm{~d}, 7 \mathrm{~d}, 14 \mathrm{~d}$ and $28 \mathrm{~d}$ is $13 \%, 10 \%, 10 \%, 8 \%, 6 \%$ and $5 \%$ the strength of the reference concrete; while the strength reduction for RCA100 decreases from $15 \%(1 \mathrm{~d})$ to $11 \%(28 \mathrm{~d})$. The strength reduction of concretes with RCAs is often considered to be resulted from an increased porosity and a weaker interfacial transition zone (ITZ) in the concretes owing to the incorporation of RCAs [5]. In addition, the test observations about the strength reduction also related with the development of the compressive strength of the concretes with time.

The variation of the age factor for the compressive strength of the concretes with time is shown in Fig. 3, which includes the test data measured on the cylindrical specimens. The compressive strength age factor is defined as the ratio of the concrete strength at any time $t$, denoted as $f_{\mathrm{c}}(\mathrm{t})$ to that at an age of $28 \mathrm{~d}$, which is denoted as $f_{\mathrm{cm}}$. The figure implies that the utilization of RCAs has a negative effect on the age factor. That is, the incorporation of the RCAs decreases the development of the concrete compressive strength with time. However, this effect decreases with the increase of the curing time and the decreases of the percentage of the RCAs. For the reference concrete RCA0, the age factor for the compressive strength is $0.49,0.75,0.85,0.92$ and 0.97 for $1 \mathrm{~d}, 2 \mathrm{~d}, 3 \mathrm{~d}, 7 \mathrm{~d}$ and $14 \mathrm{~d}$; while for RCA10, it is $0.45,0.72,0.80,0.90$ and 0.96 ; and for RCA100, it is $0.47,0.64,0.75,0.89$ and 0.98 , respectively.

In EN 1992-1-1 [6], the compressive strength of concrete at any time $f_{\mathrm{c}}(\mathrm{t})$ is calculated as

$$
f_{\mathrm{c}}(t)=\left[\beta_{\mathrm{cc}}(t)\right] f_{\mathrm{cm}}
$$


in which

$\beta_{\mathrm{cc}}(t)=\exp \left\{s\left[1-\left(\frac{28}{t}\right)^{\frac{1}{2}}\right]\right\} ; s=0.20$ for rapid hardening cement.

In ACI 209 [7], the following equation is recommended to estimate the compressive strength of concrete at any time $f_{\mathrm{c}}(\mathrm{t})$ :

$$
f_{\mathrm{c}}(t)=\frac{t}{a+b \cdot t} f_{\mathrm{cm}}
$$

where, $a$ and $b$ are parameters depending on the used type of cement and the curing condition. For concrete with rapid hardening cement and moisture-cured concrete specimens, $a=2.30, b=0.92$.

A comparison of the predictions of Eq. (1) and (2) with the test data is also given in Fig. 3. It can be seen that both models underestimate the development of the compressive strength of the concretes with time. However, the equation in EN 1992-1-1yields slightly more accurate results than the ACI 209 equation.

Fig. 4 shows the relation between the cylinder compressive strength $f_{\mathrm{c}}$ and the cube compressive strength $f_{\text {cu. The }}$ figure indicates that the use of the RCAs does not have a significant influence on the $f_{\mathrm{c}} / f_{\mathrm{cu}}$ ratio. For any curing age and any percentage of RCAs, $f_{\mathrm{c}}$ can be estimated as:

$$
f_{\mathrm{c}}=0.80 f_{\mathrm{cu}}
$$

\section{Splitting tensile strength}

The use of RCAs in concrete influences the tensile strength of the material in a different way compared with the effect on the compressive strength. The RCAs generally have a very angular shape thus the bond between the RCAs and the mortar in concrete can be stronger than that between natural aggregates and the mortar. This is positive for increasing the tensile strength of concrete. The measured data on the splitting tensile strength $f_{\mathrm{ct} \text {, sp }}$ of the concrete mixtures at each curing age are presented in Fig. 5. The tests are carried out according to the standard EN 12390-6: Testing hardened concrete -Tensile splitting strength of test specimens. It is clear that the $f_{\mathrm{ct}, \mathrm{sp}}$ of each concrete mixture increases with the curing time. At a curing age of $28 \mathrm{~d}$, the splitting tensile strength of the mixture RCA10 and RCA20 slightly increases (4\% and 6\%) in comparison to that of the reference concrete. The measured splitting tensile strengths of the other two mixtures, i.e. RCA50 and RCA100 are only slightly smaller than that of the reference concrete.

In the early age prior to 7 days, the splitting tensile strength values of RCA10 and RCA20 are generally comparable to that of the RCA0 while the strength magnitudes of the mixtures RCA50 and RCA100 reduce in comparison to that of the concrete without the RCAs. However, similar to that of the compressive strength, the reduction in the splitting tensile strength of these two mixtures compared with the reference concrete decreases with the increase of the curing time. Fig. 6 presents the age factor for the splitting tensile strength of concrete for each mixture. The figure reveals that the incorporation of the RCAs leads to a negative effect on the increase of the splitting tensile strength of the concrete with time, especially in the age prior to 7 days. However, with the decrease of the percentage of the RCAs, the influence becomes less distinct.

In EN 1992-1-1 [6], Eq. (4) is used to describe the relation between the splitting tensile strength of concrete at any time $f_{\mathrm{ct}, \mathrm{sp}}(\mathrm{t})$ and that at a curing age of $28 \mathrm{~d}, f_{\mathrm{ct}, \mathrm{spm}}$.

$$
f_{\mathrm{ct}, \mathrm{sp}}(t)=\left[\beta_{\mathrm{cc}}(t)\right]^{\alpha} f_{\mathrm{ct}, \mathrm{spm}}
$$

in which, $\beta_{\mathrm{cc}}(t)$ is defined as in Eq. (1); $\alpha$ is a parameter, for $\mathrm{t}<28 \mathrm{~d}, \alpha=1.0$.

In Fig. 6, the predictions of Eq. (4) are compared with the test data. It can be seen that Eq. (4) provides a satisfactory description of the test data.

According to ACI 318 [8], the splitting tensile strength of concrete, $f_{\mathrm{ct}, \mathrm{sp}}$, can be estimated from the compressive strength, $f_{\mathrm{c}}$, by using of the following equation:

$$
f_{\mathrm{ct}, \mathrm{sp}}=0.56 \sqrt{f_{\mathrm{c}}}
$$

Fig. 7 shows a comparison of the test data with the predicted values of Eq. (5). It can be seen from the figure that this equation produces unconservative results for concrete with compressive strength lower than $50 \mathrm{MPa}$. It should be noted that these data are derived from specimens of early ages (prior to 7 days). This is obviously resulted from the negative effect of the RCAs on the development of the concrete splitting tensile strength at early ages. One can thus conclude that Eq. (5) is not adequate for estimating the $f_{\mathrm{ct} \text {, sp }}$ of concrete at early ages. 


\section{Modulus of elasticity}

It is commonly accepted that the use of RCAs in concrete leads to a reduction of the modulus of elasticity, $E_{\mathrm{c}}$, of the material [9]. This is because the modulus of elasticity of RCAs is smaller than that of natural aggregates. The tests on the modulus of elasticity of concrete in this paper are performed according to the Belgian standard NBN B15-203: Concrete testing - Static module of elasticity with concrete. The test data on the $E_{\mathrm{c}}$ of the concretes in this study are presented in Fig. 8. It can be seen from the figure that the measured $E_{\mathrm{c}}$ value of each concrete mixture increases with the curing time. The increase mainly occurs in the first 7 days. This is similar to that of the strength properties of the concretes. In general, at any curing age, the $E_{\mathrm{c}}$ of concrete with the RCAs decreases compared with that of the reference concrete. A higher percentage of the RCAs results in smaller $E_{\mathrm{c}}$ of the concrete. At the curing age of 28 days, the measured $E_{\mathrm{c}}$ of the concrete mixture RCA10, RCA20, RCA50 and RCA100 is $95 \%, 93 \%, 88 \%$ and $88 \%$ of that of the reference concrete RCA0, respectively. This is in consistent with the test results reported in many previous studies $[9,10]$. However, the effect of the curing time and the percentage of the RCAs on the variation of the measured $E_{\mathrm{c}}$ for the mixtures with RCAs in comparison to that of the reference concrete is less remarkable.

The age factor for the modulus of elasticity, defined as the ratio of the modulus of elasticity at any time $t$, i.e. $E_{\mathrm{c}}$ $(t)$ to the modulus of elasticity at 28 days $E_{\mathrm{cm}}$, of each concrete mixture is given in Fig. 9 . The age factor for the $E_{\mathrm{c}}$ of concrete generally decreases with the increase of the percentage of the RCAs, illustrating the effect of the RCAs.

EN 1992-1-1 [6] recommended to use Eq. (6) to estimate the $E_{\mathrm{c}}(t)$ of concrete on the basis of $E_{\mathrm{cm}}$.

$$
E_{\mathrm{c}}(t)=\left[\beta_{\mathrm{cc}}(t)\right]^{0.3} E_{\mathrm{cm}}
$$

in which, $\beta_{\mathrm{cc}}(t)$ is the same function as defined in Eq. (1).

In ACI 209 [7], the following equation, given in Eq. (7) is used to describe the relation between the $E_{\mathrm{c}}(t)$ and $E_{\mathrm{cm}}$ for concrete.

$$
E_{\mathrm{c}}(t)=\sqrt{\frac{t}{a+b \cdot t}} E_{\mathrm{cm}}
$$

where, $a$ and $b$ are parameters that are defined in Eq. (2).

The predictions of Eq. (6) and (7) are also shown in Fig. 9. It is evident that the model in EN 1992-1-1 [4] provides a very accurate description of the development of the $E_{\mathrm{c}}$ of concrete with time, while the equation in ACI 209 [7] generally underestimates the increase of the $E_{\mathrm{c}}$ with time, especially prior to 7 days.

Many equations for estimating the $E_{\mathrm{c}}$ of concrete (with and without RCAs) have been developed in the past studies [10]. However, most of the equations were based on test data measured on or after 28 days. In ACI 209 [7], Eq. (8) is proposed to estimate the $E_{\mathrm{c}}$ of concrete at any time $t$ based on the concrete compressive strength at the same age, for normal weight concrete.

$$
E_{\mathrm{c}}(t)=4730 \sqrt{f_{\mathrm{c}}(t)}
$$

Fig. 10 presents the variation of the measured $E_{\mathrm{c}}$ with the compressive strength $f_{\mathrm{c}}$ (measured at different curing ages) for each concrete mixture in this study. The predictions of Eq. (8) are also shown in the figure. It can be observed from the figure that for the same concrete strength, the use of the RCAs generally decreases the $E_{\mathrm{c}}$ of concrete. The equation provides a lower bound of the test data, indicating the predicted $E_{\mathrm{c}}$ values are on the safe side when it is used for design of structural elements.

\section{CONCLUSIONS}

This paper presents an experimental study on the mechanical properties of concrete with high quality RCAs at early ages. A total of 5 concrete mixtures with different replacing percentages of the RCAs (in volume) are tested at $1 \mathrm{~d}, 2 \mathrm{~d}, 3 \mathrm{~d}, 7 \mathrm{~d}, 14 \mathrm{~d}$ and $28 \mathrm{~d}$. The effect of the percentage of the RCAs and the curing time on the compressive strength, splitting tensile strength and modulus of elasticity of the concrete is investigated. Based on the interesting test data and discussions, the following conclusions can be drawn:

(1) The compressive strength, splitting tensile strength and modulus of elasticity of the concrete with the RCAs increases with the increase of the curing time. The development in the strength and modulus of elasticity of the concrete mainly occurs in the first 7 days, which is similar to that of conventional concrete with natural aggregates;

(2) The utilization of the RCAs in this paper in concrete has a negative effect on the development of the mechanical properties of the material. This effect becomes less remarkable with the increase of the curing age; 
(3) The influence of the RCAs on the increase of the concrete mechanical properties with curing time can be minimized through limiting the amount of RCAs. From this viewpoint, it is possible to incorporate small amount of (high quality) RCAs in producing precast structural concrete;

(4) More test data are required to develop models that can describe the time-dependent mechanical properties of concrete with RCAs;

(5) In addition to the strength and modulus of elasticity, information about the creep and shrinkage behavior of concrete with RCAs at early ages is also required. This kind of research will allow a more rational assessment on the possibility of incorporation of RCAs in precast prestressed concrete.

\section{ACKNOWLEDGMENTS}

This work has been supported by a start-up funding (No. STG/16/011) granted to the second author from KU Leuven - University of Leuven, Belgium. This financial support is gratefully acknowledged.

\section{NOTATION}

$\begin{array}{ll}a, b & \text { coefficients depending on the used cement type and the curing conditions } \\ E_{\mathrm{c}} & \text { modulus of elasticity of concrete }(\mathrm{MPa}) \\ E_{\mathrm{c}}(\mathrm{t}) & \text { modulus of elasticity of concrete at any time } t(\mathrm{MPa}) \\ E_{\mathrm{cm}} & \text { compressive strength at at } 28 \text { days }(\mathrm{MPa}) \\ f_{\mathrm{c}} & \text { cylinder compressive strength of concrete }(\mathrm{MPa}) \\ f_{\mathrm{c}}(\mathrm{t}) & \text { compressive strength at any time } t(\mathrm{MPa}) \\ f_{\mathrm{cm}} & \text { compressive strength at } 28 \text { days }(\mathrm{MPa}) \\ f_{\mathrm{ct}, \mathrm{sp}} & \text { splitting tensile strength of concrete }(\mathrm{MPa}) \\ f_{\mathrm{ctm}, \mathrm{sp}}(t) & \text { splitting tensile strength of concrete at any time } t(\mathrm{MPa}) \\ f_{\mathrm{ct}, \mathrm{spm}} & \text { splitting tensile strength of concrete at } 28 \text { days }(\mathrm{MPa}) \\ f_{\mathrm{cu}} & \text { cube compressive strength of concrete }(\mathrm{MPa}) \\ s & \text { a coefficient depending on the used type of cement. } \\ t & \text { age of the concrete (days) } \\ \rho_{\mathrm{a}} & \text { absolute density of aggregates }\left(\mathrm{kg} / \mathrm{m}^{3}\right) \\ \rho_{\mathrm{rd}} & \text { oven-dried particle density of aggregates }\left(\mathrm{kg} / \mathrm{m}^{3}\right) \\ \rho_{\mathrm{ssd}} & \text { saturated and surface-dry particle density of aggregates }\left(\mathrm{kg} / \mathrm{m}^{3}\right) \\ \beta_{\mathrm{cc}}(t) & \text { a coefficient which depends on the age of the concrete } t \\ \text { RCA } & \text { recycled concrete aggregates } \\ \text { WA } & \text { water absorption of the aggregates after } 24 \mathrm{~h} \text { submersion }(\%)\end{array}$

\section{REFERENCES}

[1] Notermann, B. et al., "Recybet Roadmap - Ontwikkeling van een nieuwe waardeketen voor de valorisatie van betonpuin in betonproducten”, Belgium, 2016.

[2] Brandes M.R. and Kurama Y.C., "Use of Recycled Concrete aggregates in Precast/Prestressed Concrete", Procedia Engineering, Vol.145, 2016, pp. 1338-1345.

[3] Soutsos M. N., Tang K. and Millard S. G., "Concrete building blocks made with recycled demolition aggregate", Construction and Building materials, Vol. 25, No. 2, 2011, pp. 726-735.

[4] Tam, V. W. Y., Gao, X., and Tam, C. M., "Microstructural analysis of recycled aggregate concrete produced from two-stage mixing approach", Cement and Concrete Research, Vol. 35, No. 6, 2005, pp. 1195-1203.

[5] Li, J., "Study on mechanical behavior of recycled aggregate concrete", Master thesis, Tongji University, Shanghai, 2004, 122 pp.

[6] EN 1992-1-1: Eurocode 2: Design of concrete structures - Part 1-1: General rules and rules for buildings. Brussels, 2004.

[7] ACI Committee 209., "Prediction of creep, shrinkage, and temperature effects in concrete structures", American Concrete Institute, Farmington Hills, Mich., 2002.

[8] ACI Committee 318., "Building code requirements for structural concrete (ACI 318M-14) and commentary (ACI 318RM-14)", American Concrete Institute, Farmington Hills, Mich., 2014.

[9] Xiao, J., Li, J., and Zhang, Ch., "Mechanical properties of recycled aggregate concrete under uniaxial loading", Cement and Concrete Research, Vol. 35, No. 6, 2005, pp. 1187-1194.

[10] Xiao, J., Li, J., and Zhang, Ch., "On relationships between the mechanical properties of recycled aggregate concrete: an overview”, Materials and Structures, Vol. 39, No. 6, 2006, pp. 655-664. 
TABLES AND FIGURES

Table 1 - Properties of aggregates

\begin{tabular}{|c|c|c|c|c|}
\hline Aggregates & $\rho_{\mathrm{a}}\left(\mathrm{kg} / \mathrm{m}^{3}\right)$ & $\mathrm{P}_{\mathrm{rd}}\left(\mathrm{kg} / \mathrm{m}^{3}\right)$ & $\rho_{\text {ssd }}\left(\mathrm{kg} / \mathrm{m}^{3}\right)$ & $\mathrm{WA}_{24}(\%)$ \\
\hline Sand $(0-4 \mathrm{~mm})$ & 2640 & 2620 & 2630 & 0.10 \\
\hline Limestone $(2-6.3 \mathrm{~mm})$ & 2650 & 2600 & 2620 & 0.76 \\
\hline Limestone $(6.3-14 \mathrm{~mm})$ & 2660 & 2610 & 2630 & 0.61 \\
\hline RCA $(6.3-14 \mathrm{~mm})$ & 2510 & 2260 & 2360 & 4.80 \\
\hline
\end{tabular}

Table 2 - Concrete mixtures

\begin{tabular}{|c|c|c|c|c|c|}
\hline & RCA0 & RCA10 & RCA20 & RCA50 & RCA100 \\
\hline CEM I 52.5R $\left(\mathrm{kg} / \mathrm{m}^{3}\right)$ & 400 & 400 & 400 & 400 & 400 \\
\hline W/C $\mathrm{eff}^{3}$ & 0.48 & 0.48 & 0.48 & 0.48 & 0.48 \\
\hline Sand 0/4 $\left(\mathrm{kg} / \mathrm{m}^{3}\right)$ & 780 & 780 & 780 & 780 & 780 \\
\hline Limestone 2-6.3mm $\left(\mathrm{kg} / \mathrm{m}^{3}\right)$ & 196 & 196 & 196 & 196 & 196 \\
\hline Limestone 6.3-14mm $\left(\mathrm{kg} / \mathrm{m}^{3}\right)$ & 785 & 706 & 628 & 392 & 0 \\
\hline RCA 6.3-14 $\left(\mathrm{kg} / \mathrm{m}^{3}\right)$ & 0 & 74 & 148 & 371 & 742 \\
\hline Superplasticizer $\left(\mathrm{kg} / \mathrm{m}^{3}\right)$ & 1.3 & 1.3 & 1.3 & 1.3 & 1.3 \\
\hline Compensation water $\left(\mathrm{kg} / \mathrm{m}^{3}\right)$ & 7 & 10 & 13 & 22 & 38 \\
\hline Slump $(\mathrm{mm})$ & 210 & 197 & 195 & 192 & 190 \\
\hline
\end{tabular}

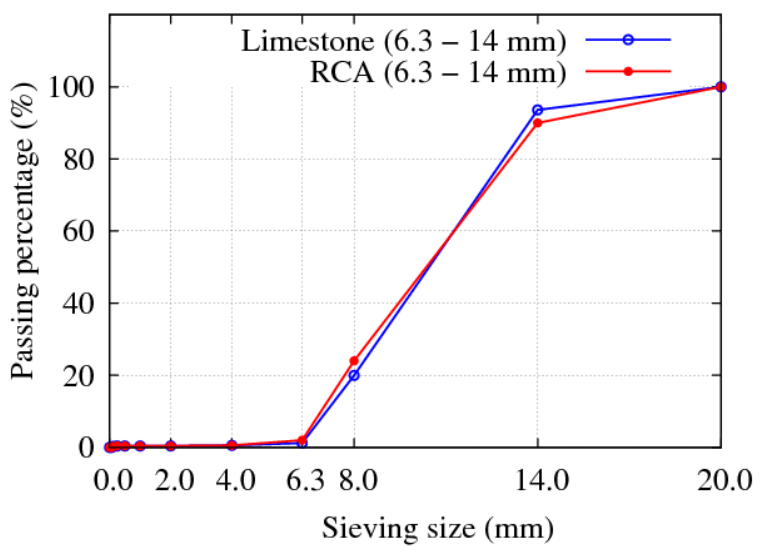

Fig. 1 - Sieving analysis of aggregates

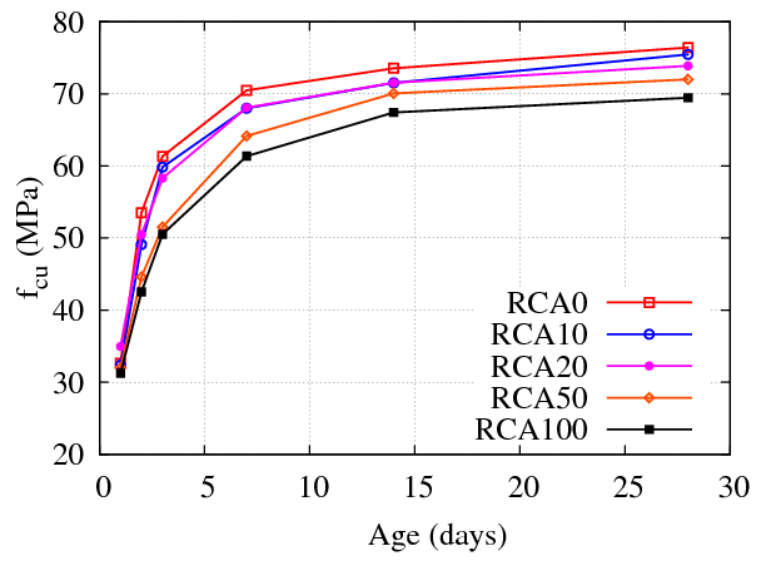

(a) Cube compressive strength $\left(f_{\text {cu }}\right)$

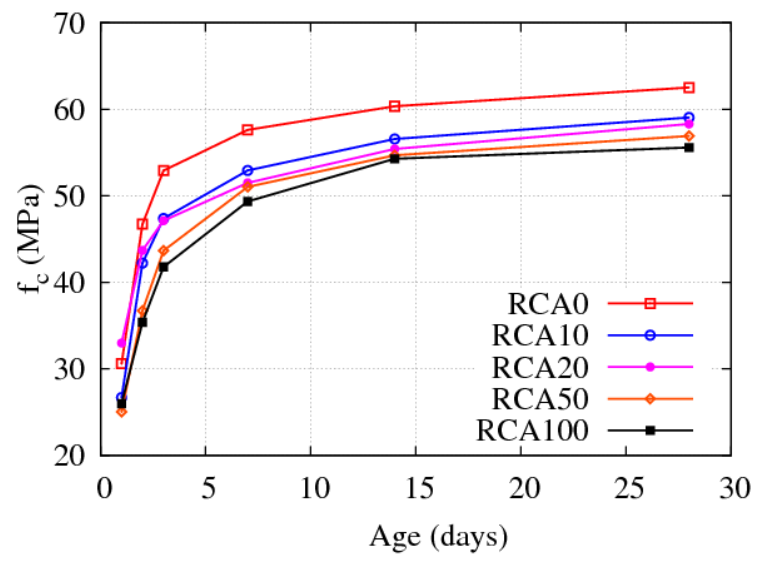

(b) Cylinder compressive strength $\left(f_{\mathrm{c}}\right)$

Fig. 2 - Development of compressive strength with time 


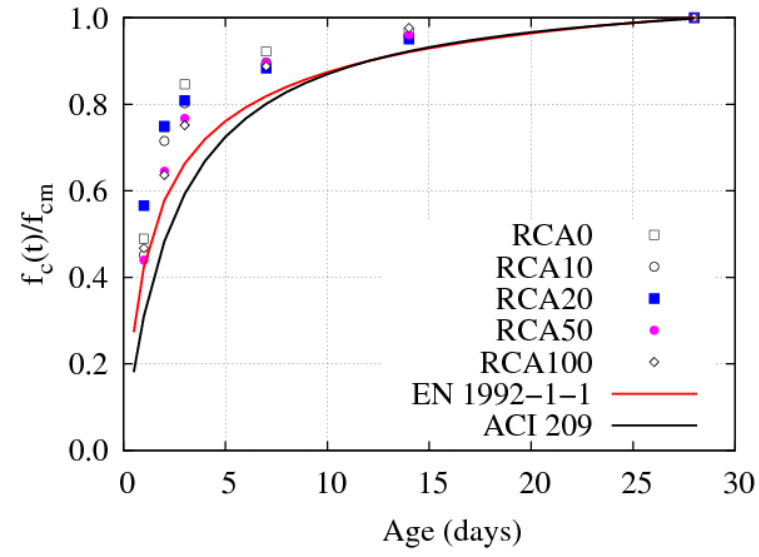

Fig. 3 - Age factor for compressive strength of concrete vers. Time

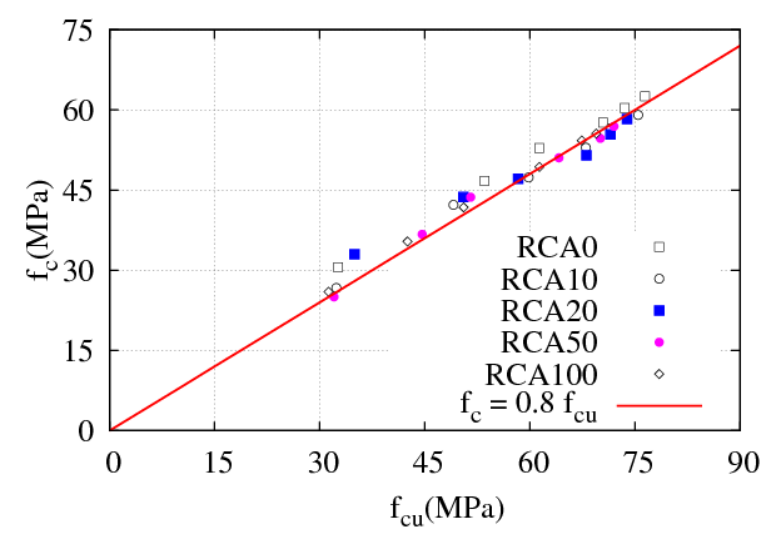

Fig. 4 - Relation between $f_{\mathrm{c}}$ and $f_{\text {cu }}$

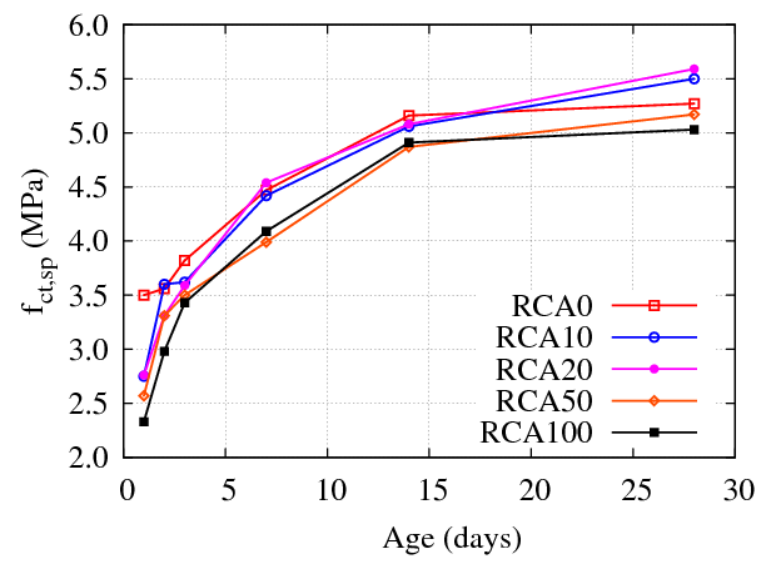

Fig. 5 - Development of splitting tensile strength of concrete with time 
Mechanical Properties of Concrete with Recycled Aggregate at Early Ages

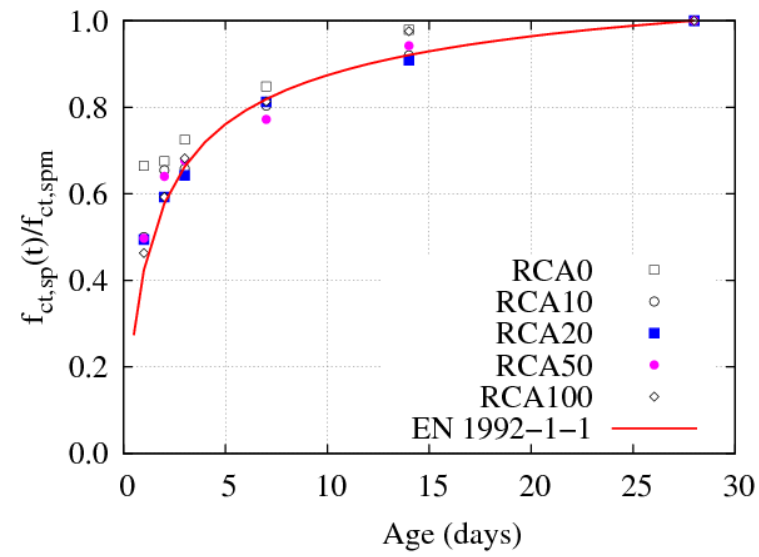

Fig. 6 -Age factor for the splitting tensile strength of concrete vers. time

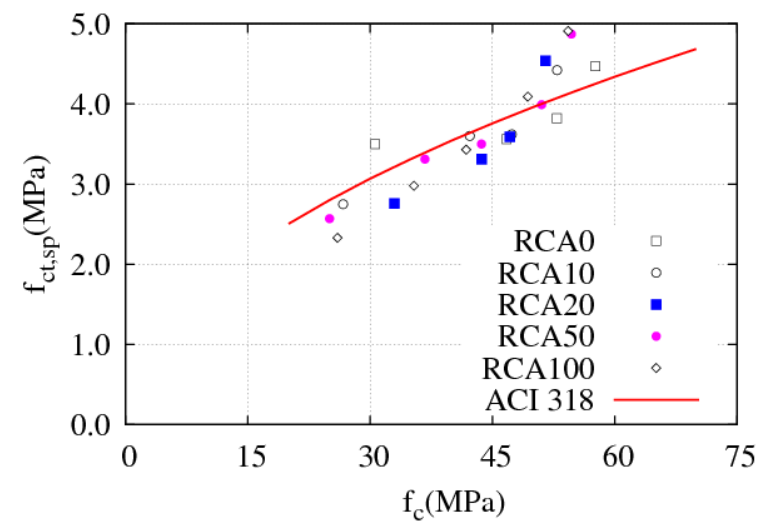

Fig. 7 - Relation between $f_{\text {ct,sp }}$ and $f_{\mathrm{c}}$

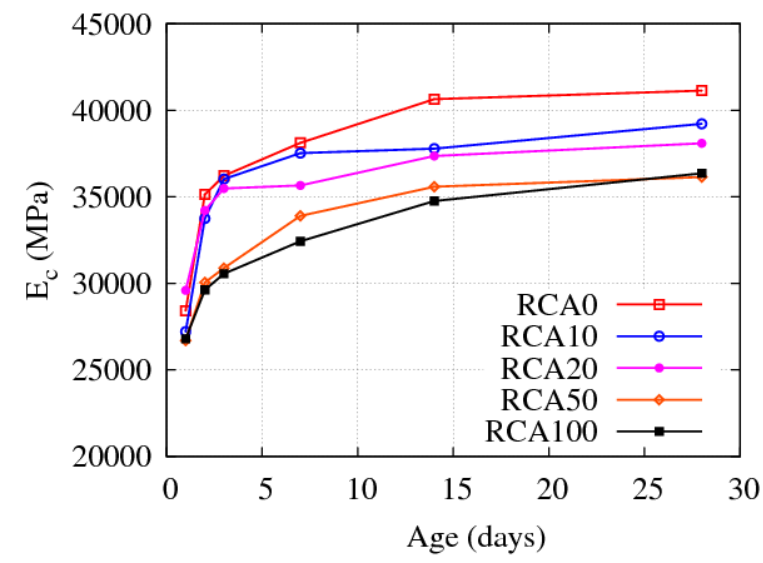

Fig. 8 - Development of modulus of elasticity of concrete with time 


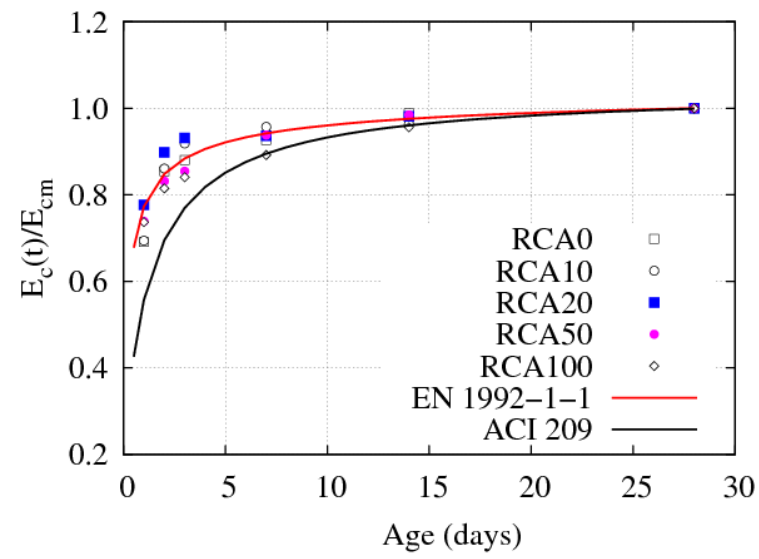

Fig. 9 - Age factor for modulus of elasticity of concrete vers. time

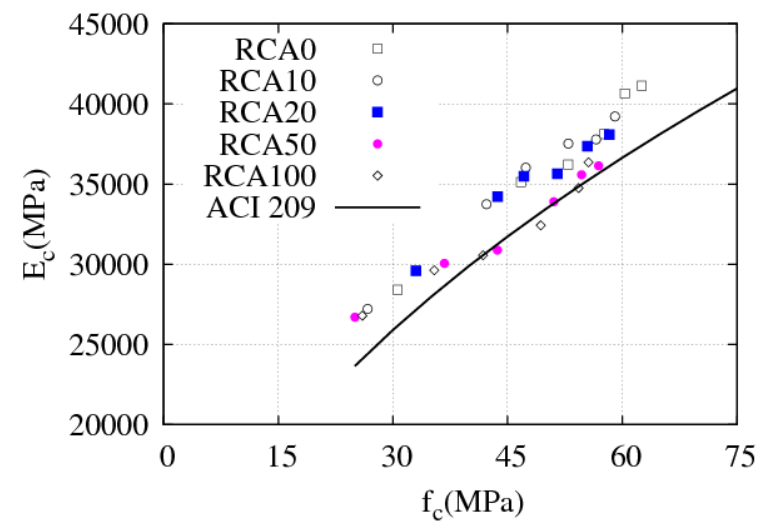

Fig. 10 - Relation between $E_{\mathrm{c}}$ and $f_{\mathrm{c}}$ 